\title{
The Treatment Experience of Different Types of Flaps for Repairing Soft Tissue Defects of the Heel
}

\author{
Bo Feng* \\ Guang-Ming Dai* \\ Yong-Jun Wang \\ Lan Zhang \\ Ke-Cheng Niu
}

Department of Foot and Ankle Surgery, The Third Affiliated Hospital of Inner Mongolia Medical University, Baotou, 0I40 I0, People's Republic of China

*These authors contributed equally to this work
Correspondence: Bo Feng

Tel +86 I3347/73738

Email femgbo@aliyun.com
Objective: To summarize the clinical application effects of three different types of flaps for repairing soft tissue defects of the heel, and to discuss the importance of tissue repair and heel reconstruction.

Methods: A total of 46 cases with skin tissue defects of the heel with deep tissue exposure were treated. The reasons for the defect were trauma $(n=26)$, burns and electric shocks $(n=$ 12), chronic ulcers $(n=2)$, postoperative infection of the calcaneus and Achilles tendon ( $\mathrm{n}$ $=5$ ), and tumor resection $(\mathrm{n}=1)$. The scope of wound defect was $2.0 \times 2.5$ to approximately $15.0 \times 20.0 \mathrm{~cm}$. The flaps used were medial plantar island flaps $(\mathrm{n}=9)$, distal pedicled sural neurovascular island flaps $(\mathrm{n}=23)$, and free anterolateral thigh (perforator) flaps $(\mathrm{n}=14)$. The flap cutting range was $3.0 \times 3.5$ to approximately $16.0 \times 22.0 \mathrm{~cm}$.

Results: After surgery, all 46 flaps survived. In two cases, patients experienced partial epidermal necrosis at the distal end of the flap that healed after local dressing exchange, and after this treatment, the complete skin grafts survived. Follow-up was conducted in 40 cases, with an average follow-up duration of 8.2 months (3-44 months) and the two-point discrimination of 5$14 \mathrm{~mm}$. The average American Orthopaedic Foot and Ankle Society scale was 89.2 points with good flap color and texture, satisfactory appearance, and normal gait.

Conclusion: The repair method should be selected according to the" 5 -zone method": The plantar medial island flap is suitable for small area $(<5 \mathrm{~cm})$ of medial, posterior and plantar defects. The distal pedicled sural neurovascular flap is suitable for lateral, posterior, and medium-range $(6-10 \mathrm{~cm})$ joint area defects. The free anterolateral thigh perforator flap is suitable for large-scale $(>10 \mathrm{~cm})$ joint area defects.

Keywords: surgical flap, heel, functional reconstruction

Heel is an important functional part of the human body, with special anatomical characteristics and weight-bearing functions. In clinical practice, it was common to encounter various degrees of soft tissue defects in the heel caused by factors such as trauma, burns, infection and necrosis, chronic ulcers, and tumor resection. While covering the trauma with a flap, abrasion resistance, function, and aesthetic factors need to be considered. ${ }^{1,2}$

To better guide the selection of the appropriate flap in clinical applications, some researchers have suggested various zones of the heel. In 2010, Stevenson et $\mathrm{al}^{3}$ proposed three basic principles for the repair of heel trauma: sensation, stability, and satisfactory appearance. Previously, different types of flaps have been adopted to repair wounds in the same area, with varying results. ${ }^{1,4-7}$ Hollenbeck $^{8}$ proposed the subunit principle, which is a seven-zone method for the subunit repair of the foot and ankle, according to different functional and aesthetic requirements, in which the heel is divided into four zones 
focusing on highly functional, wear-resistant, moderate volume, and low aesthetic requirements, and this research suggested that the anterolateral thigh flap should be the preferred method, followed by the latissimus dorsi flap. Hallock ${ }^{9}$ modified this zoning method, by dividing the heel into four zones and the posterior heel region into seven zones and suggesting the pedicled flap as a secondary option. Through anatomical studies, Chen et $\mathrm{al}^{10}$ divided the heel into five zones: the plantar, posterior, supra-heel, inner, and outer, according to the different degrees of gravity and friction applied to each part. Wang ${ }^{11}$ divided the plantar skin into the heel, anterior metatarsal, lateral, and metatarsal arch zones according to the primary and secondary weight-bearing functions, in which the former three are classified as weightbearing zones. According to the anatomical and physiological characteristics and functions of the skin around the heel, Zhang $^{12}$ divided the heel into two zones: the weight-bearing and the non-weight-bearing zones. The weight-bearing zone is the plantar zone of the heel, and the non-weight-bearing zone includes three parts namely the inner, the outer, and the posterior zones of the heel. We believe that cross-regional injuries are commonly encountered in clinical practice. To facilitate the selection of the repair method, we proposed the 5-zone method, namely the inner heel, the heel-plantar, the posterior heel, the outer heel, and the joint zone, based on the location to be repaired.

This study reviewed 46 cases of heel tissue defects, divided them according to the "5-zone method", and analyzed factors such as flap types, complications, and survival rates. Meanwhile, we explored the effect of neuroanastomosis and non-neural anastomosis on the prognosis of patients during the repair of skin flaps. All cases were followed up for an average of 8.2 months with good results. The details are reported as follows.

\section{Materials and Methods}

\section{General Characteristics}

The present study included 46 cases (26 on the left heel and 20 on the right) including 40 males and 6 females, with an average age of 28.6 y (8-69 y). The reasons for the defect were trauma $(n=26)$, burns and electric shocks $(n=$ 12), chronic ulcers $(n=2)$, postoperative infection of the calcaneus and Achilles tendon $(\mathrm{n}=5)$, and tumor resection $(\mathrm{n}=1)$. The scope of wound defect was $2.0 \times 2.5$ to approximately $15.0 \times 20.0 \mathrm{~cm}$. The flaps used were medial plantar island flaps $(\mathrm{n}=9)$, distal pedicled sural neurovascular island flaps $(n=23)$, and free anterolateral thigh (perforator) flaps $(\mathrm{n}=14)$. The flap cutting range was $3.0 \times 3.5$ to approximately $16.0 \times 22.0 \mathrm{~cm}$. The details of the patient's baseline information, defect reason, heel zone, and defect location are shown in Table 1.

\section{Results}

\section{Surgical Methods}

Preoperatively, a Doppler probe was routinely used to locate the vascular perforator point, and the wound was

Table I The Details of the Patient's Baseline Information

\begin{tabular}{|c|c|c|c|c|c|}
\hline S. No & \multicolumn{2}{|c|}{ Variables } & The Medial Plantar Island & The Distal Pedicled Sural Neurovascular & The Free Anterolateral Thigh \\
\hline \multirow[t]{2}{*}{ I } & \multirow[t]{2}{*}{ Gender } & Male & 8 (88.9\%) & $20(87 \%)$ & 12 (85.7\%) \\
\hline & & Female & I (11.1\%) & $3(13 \%)$ & $2(14.3 \%)$ \\
\hline 2 & Age & Mean (in years) & $\begin{array}{c}\text { Average age of } 32.6 \text { y (24-69 } \\
y)\end{array}$ & Average age of 26.6 y $(8-64 y)$ & Average age of 27.3 y (14-57 y) \\
\hline \multirow[t]{5}{*}{3} & \multirow{5}{*}{$\begin{array}{c}\text { Mechanism of } \\
\text { injury }\end{array}$} & Trauma & $3(11.5 \%)$ & $16(61.5 \%)$ & $7(27 \%)$ \\
\hline & & $\begin{array}{l}\text { Burns, electric } \\
\text { shocks }\end{array}$ & $3(25.0 \%)$ & $5(41.7 \%)$ & $4(33.3 \%)$ \\
\hline & & Infection & I (20.0\%) & $2(40.0 \%)$ & $2(40.0 \%)$ \\
\hline & & Chronic ulcer & I (50.0\%) & 0 & I (50.0\%) \\
\hline & & $\begin{array}{l}\text { After tumor } \\
\text { resection }\end{array}$ & I (100\%) & 0 & 0 \\
\hline 4 & Flap Size & Mean (in $\mathrm{cm}$ ) & $\begin{array}{l}3.0 \mathrm{~cm} \times 3.5 \mathrm{~cm}^{\circ} \\
\sim 4.0 \mathrm{~cm} \times 6.5 \mathrm{~cm}\end{array}$ & $5.0 \mathrm{~cm} \times 8.0 \mathrm{~cm} \sim 9.0 \mathrm{~cm} \times 15.0 \mathrm{~cm}$ & $5.0 \mathrm{~cm} \times 9.5 \mathrm{~cm} \sim 16.0 \mathrm{~cm} \times 22.0 \mathrm{~cm}$ \\
\hline
\end{tabular}


expanded until the granulation tissue was fresh. The flap was designed in strict accordance with the point, line, surface, and arc design, and the excision area was enlarged by approximately $2 \mathrm{~cm}$ when compared with the area of the defect. The pedicled flaps were transferred either explicitly or implicitly by vascular pedicles, fascial pedicles, or dermal pedicles, depending on the situation. The flaps all carried sensory nerves and were anastomosed to the recipient area, and the donor area, located on the medial axis of the foot, was implanted with skin. The remaining donor areas were directly sutured $(<8 \mathrm{~cm})$ or implanted with skin.

1. Medial plantar island flap: The body projection of the medial plantar artery, ie, the line extending from the anterior border of the medial ankle to the head of the first and second metatarsals, was used as the flap axis, with the rotation point approximately $1 \mathrm{~cm}$ below the medial ankle. The flap was cut reversely to a size of $3.0 \times 3.5$ to $4.0 \times 6.5 \mathrm{~cm}$ and carried the medial plantar nerve branch.

\section{Typical Case}

A female patient of 59 years was admitted on June 27, 2016, with a complaint of a "left heel mass of unknown nature." On completion of the relevant examinations, "mass resection, repair with the plantar medial island flap and skin grafting" was conducted on June 29. The mass and $1 \mathrm{~cm}$ of the surrounding tissue were completely resected during the operation. The flap area was $4.0 \times 5.0 \mathrm{~cm}$ and was transferred explicitly, and the flap and the implant area both survived after surgery. The pathological report revealed squamous cell carcinoma. The patient was followed up for 44 months with no recurrence of the mass. The two-point discrimination (2PD) was $5 \mathrm{~mm}$. The patient could walk without obstacles and with a satisfactory appearance, as shown in Figure 1.

2. The distal pedicled sural neurovascular flap: The midpoint of the line between the tip of the lateral malleolus and the Achilles tendon and the midpoint of the popliteal fossa were taken as the axis, and $5 \mathrm{~cm}$ above the lateral malleolus was the point of flap rotation. The flap was cut in the form of a "tennis racket" and "propeller" and carried the lateral sural cutaneous nerve. The cutting range was $5.0 \times 8.0$ to approximately $9.0 \times 15.0 \mathrm{~cm}$, and the flap was transferred explicitly to the recipient area.

\section{Typical Case}

A 30-year-old male patient was admitted to the hospital on December 25, 2016, owing to two weeks of skin necrosis after a calcaneal fracture. On the third day of admission, the "trauma expanding and vacuum sealing drainage (VSD) coverage" was conducted, and the "trauma expanding, distally pedicled sural nerve nutrient vessel flap repair" was conducted on January 4, 2017. The necrotic tissue and surrounding inflammatory granulation tissue were resected during the operation. The flap area was $3.5 \times 6.5 \mathrm{~cm}$, the pedicle length was $4.5 \mathrm{~cm}$, and the lateral sural cutaneous nerve was anastomosed. The donor site was sutured directly, and the flap survived. The patient

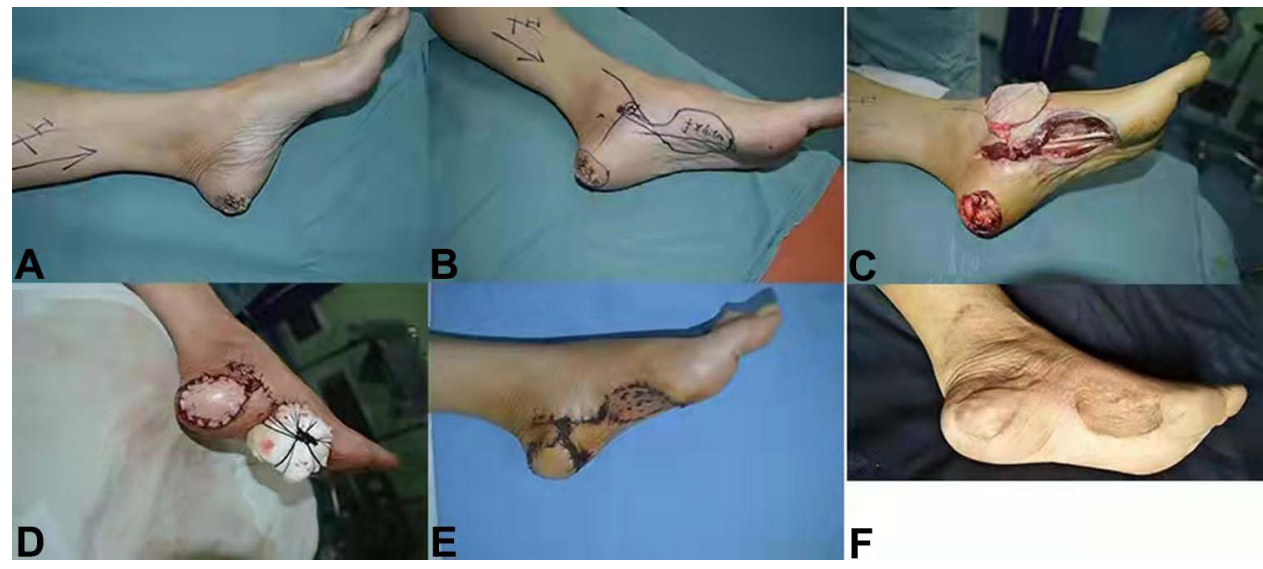

Figure I Excision of medial metatarsal skin mass in left heel, repair of medial plantar island flap. (A) Preoperative appearance photo, Mass size $3.0 \mathrm{~cm} \times 3.0 \mathrm{~cm}$. (B) Flap design. (C) Flap extraction, size $4.0 \mathrm{~cm} \times 5.0 \mathrm{~cm}$. (D) Flap suture. (E) Flap survival (3 weeks). (F) Followed up 44 months after operation, 2 PD $5 \mathrm{~mm}$, no tumor recurrence, normal function. 
was admitted to the hospital on November 29, 2018 for shape modification and removal of the internal fixation. The patient was followed up for 23 months, with a 2PD of $9 \mathrm{~mm}$ and good function and appearance (Figure 2).

3. The free anterolateral thigh (perforator) flap: The anterior superior iliac spine and the lateral edge of the patella were adopted as the axis, and the flap was designed with the perforator point as the center. The lateral edge was incised and sharply separated medially under the broad fascia (the perforator flap was separated on the broad fascia surface, and a $2.0 \times 2.0 \mathrm{~cm}$ annular broad fascial disc was cut around the perforator), and the flap carried the lateral femoral cutaneous nerve. With the confirmation of the perforator, anatomical separation was performed reversely, and according to the location of the vessels in the recipient area, a certain length of the descending branch of the lateral spino-femoral vessels was cut and anastomosed, with a flap size of $5.0 \times 9.5$ to $16.0 \times 22.0 \mathrm{~cm}$.

\section{Typical Case}

A 63-year-old male patient was admitted to the hospital on August 21, 2016 for "1-month postoperative necrosis of the right heel avulsion caused by machine compression". After hospitalization, the patient undertook "trauma expanding, VSD coverage" on August 23 and "trauma expanding, ipsilateral anterolateral femoral flap repair and skin grafting" on September 8. The flap area was $12.5 \times 18 \mathrm{~cm}$, and the lateral femoral cutaneous nerve was intraoperatively anastomosed with the saphenous nerve. The flap survived with primary wound healing. The patient was followed up for 42 months with a $2 \mathrm{PD}$ of $11 \mathrm{~mm}$. The appearance was satisfying. The patient wore a heel pad to walk without obvious obstacles (Figure 3).

Routine therapy was conducted postoperatively, together with symptomatic and hyperbaric oxygen therapy for patients with flap crises. Adjuvant treatment with elastic stockings and compression bandages was conducted four weeks after surgery, and silicone heel pads were worn in the case of weight-bearing.

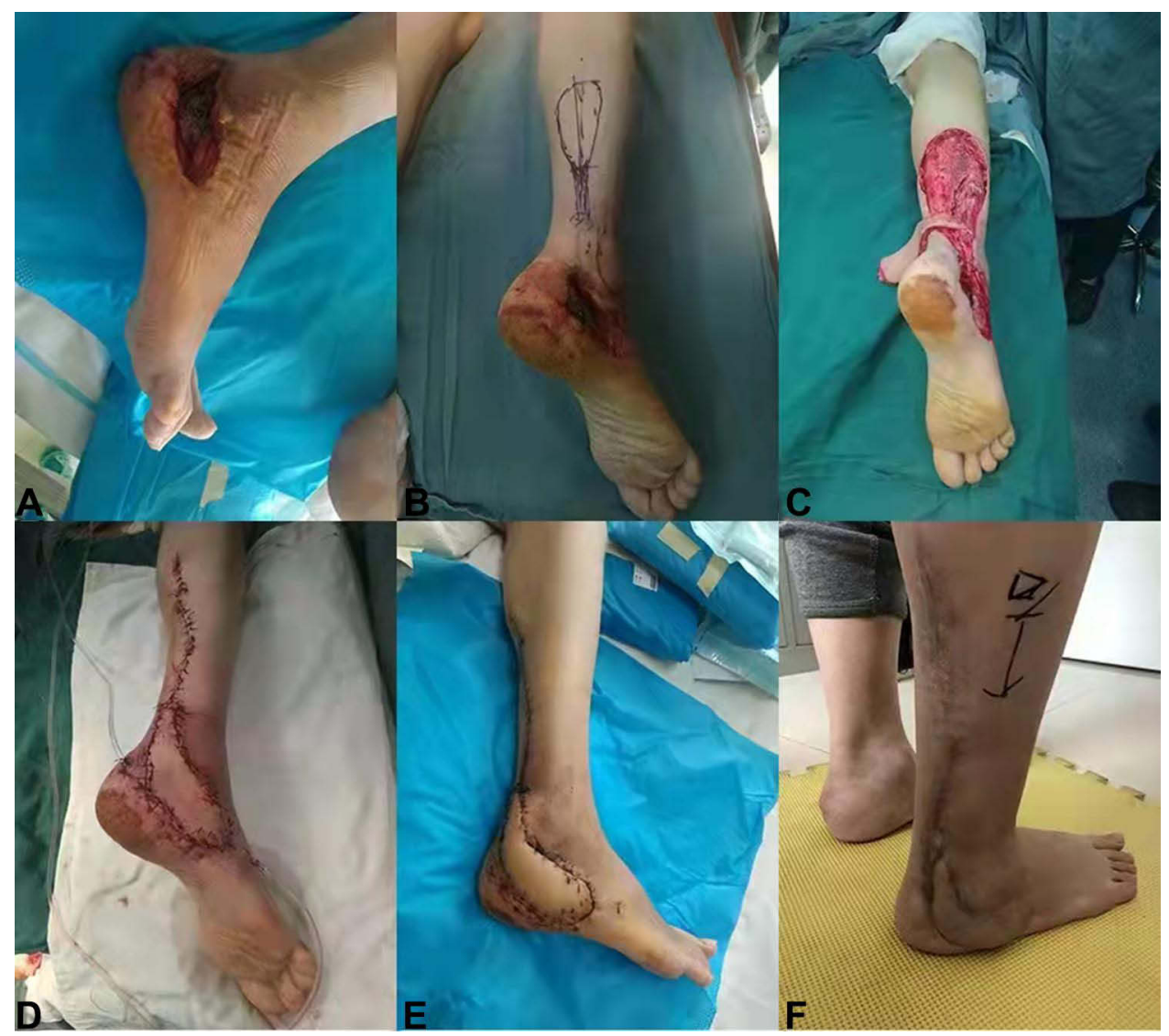

Figure 2 Bone exposure after right calcaneus fracture, distal pedicled sural nerve nutritional blood vessel flap. (A) Preoperative wound situation, exposed steel plate. (B) Flap design. (C) Flap extraction, area $3.5 \mathrm{~cm} \times 6.5 \mathrm{~cm}$, pedicle length $4.5 \mathrm{~cm}$. (D) Covered by flap, the donor area is closed directly. (E) Primary wound healing (2 weeks). (F) 23 months after operation, 2 PD $9 \mathrm{~mm}$, satisfactory function and appearance. 


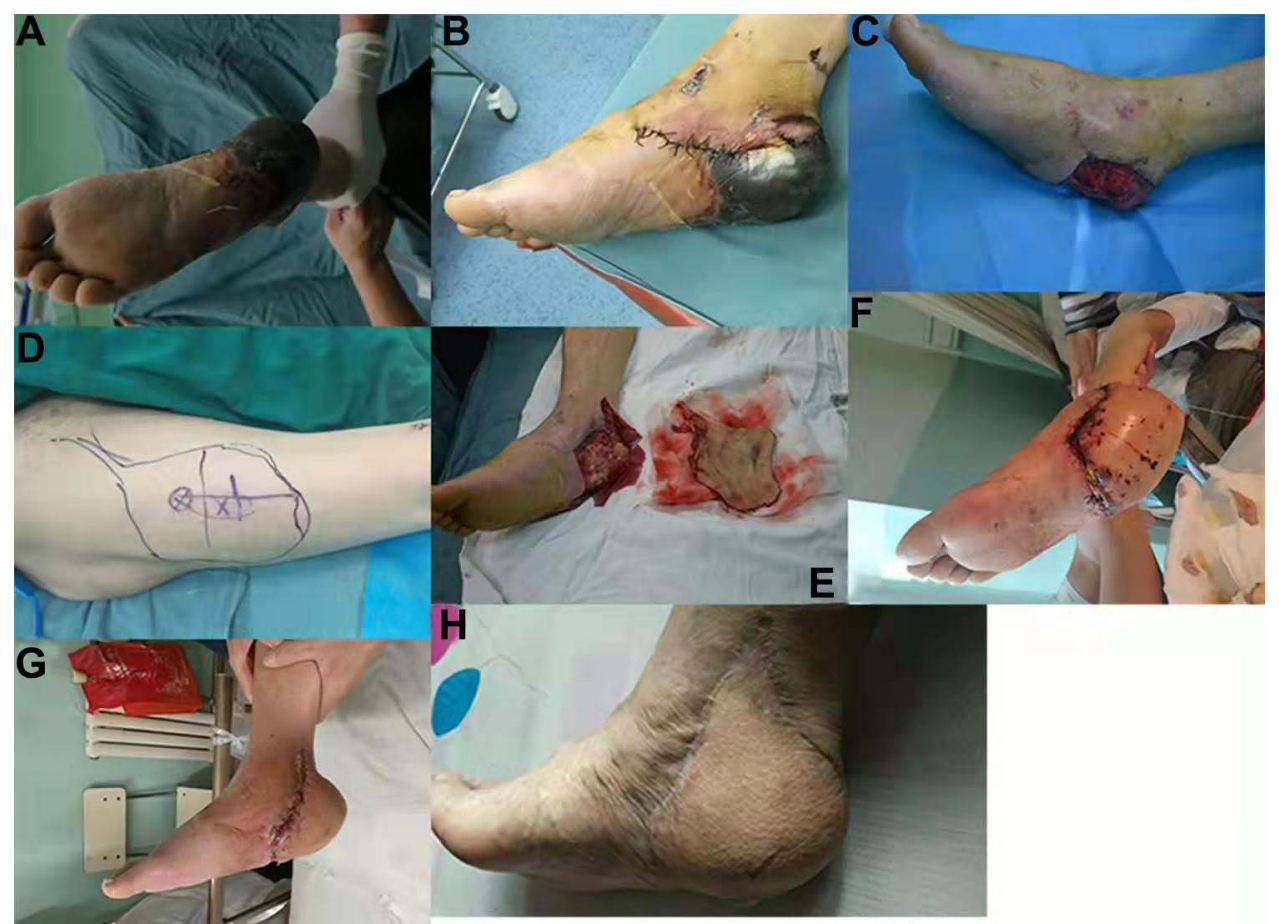

Figure 3 Avulsion injury and necrosis of skin and soft tissue of right calcaneus, repair of anterior lateral perforator flap of ipsilateral femur. (A and B) Preoperative appearance photo. (C) Wound surface after VSD coverage. (D) Ipsilateral femoral anterolateral flap design, size $12.5 \mathrm{~cm} \times 18 \mathrm{~cm}$. (E) Split flap. (F) Postoperative appearance (I week). (G) Postoperative appearance (3 weeks). (H) 42 months follow-up after operation, 2PDI I mm, satisfactory function and appearance.

\section{Postoperative Efficacy}

After surgery, all 46 flaps survived. Two cases had epidermal necrosis in the distal part of the flaps, which healed after local debridement and dressing change. Shape modification was conducted in 3 cases, and follow-up was conducted in 40 cases, with an average follow-up duration of 8.2 months (3-44 months) and a 2PD of 5-14 mm. The average American Orthopaedic Foot and Ankle Society scale was 89.2 points with good flap color and texture, satisfactory appearance, and normal gait. We divided 46 cases of heel injuries according to the " 5 -zone method", and statistically analyzed the flap types, complications, and flap survival rate, as shown in Figure 4 and Table 2.

\section{Discussion}

A biomechanical analysis of the foot shows that the calcaneus can carry $80 \%$ of the bodyweight during standing. ${ }^{13}$ The epidermis on the metatarsal side of the heel is approximately $1.4 \mathrm{~mm}$ thick, with dense subcutaneous tissue that is filled with fatty tissue, forming a thick and tough fat pad with the role of absorbing and redistributing pressure. At the same time, due to the existence of vertical fiber bundles connected with the deep tissue, the heel may play the role of counteracting shear forces. ${ }^{14,15}$ The skin

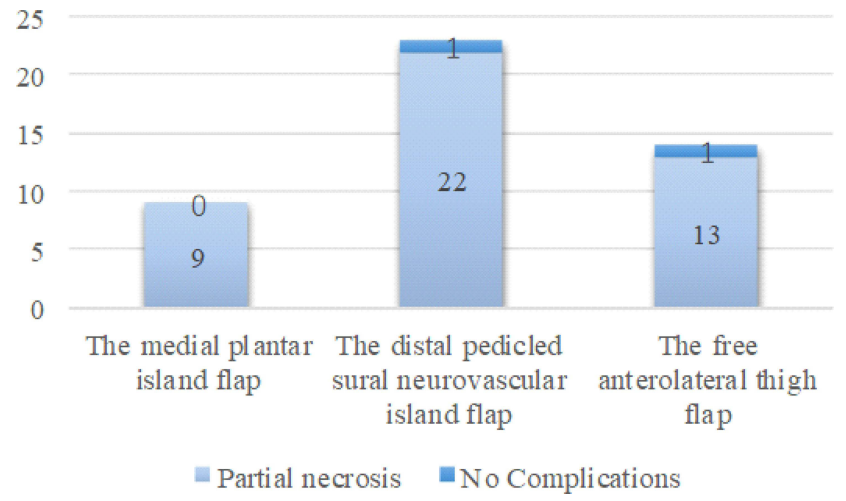

Figure 4 A histogram of the complications.

on the medial, lateral, and posterior sides of the heel, which gradually thickens from top to bottom, has a fine distribution of sensory nerve fibers. The medial and lateral heel skin is thin and mainly covers the calcaneus, ankle canal, and internal anatomical structures, while the posterior heel skin is slightly thicker and covers the distal end of the Achilles tendon and the posterior side of the calcaneus.

Clinically, skin and soft tissue defects of the heel caused by trauma and other causes are relatively common, and the requirements for repairing such injuries are stringent, not only to achieve trauma repair but also to restore 
Table 2 The Details of the "5-Zone Method" Locations, Complications and Survival Rates

\begin{tabular}{|c|c|c|c|c|c|}
\hline S. No & \multicolumn{2}{|c|}{ Variables } & The Medial Plantar Island & The Distal Pedicled Sural Neurovascular & The Free Anterolateral \\
\hline \multirow[t]{5}{*}{ I } & \multirow[t]{5}{*}{$\begin{array}{l}\text { 5- zone method } \\
\text { location }\end{array}$} & $\begin{array}{c}\text { The inner } \\
\text { heel }\end{array}$ & $2(22.2 \%)$ & 0 & 0 \\
\hline & & $\begin{array}{l}\text { The heel- } \\
\text { plantar }\end{array}$ & $4(44.5 \%)$ & 0 & 0 \\
\hline & & $\begin{array}{c}\text { The posterior } \\
\text { heel }\end{array}$ & $3(33.3 \%)$ & $6(26.1 \%)$ & 0 \\
\hline & & $\begin{array}{c}\text { The outer } \\
\text { heel }\end{array}$ & 0 & $6(26.1 \%)$ & 0 \\
\hline & & $\begin{array}{l}\text { The joint } \\
\text { zone }\end{array}$ & 0 & II (47.8\%) & $14(100 \%)$ \\
\hline \multirow[t]{2}{*}{2} & \multirow[t]{2}{*}{ Complications } & $\begin{array}{l}\text { Partial } \\
\text { necrosis }\end{array}$ & 0 & I (4.3\%) & I (7.I\%) \\
\hline & & $\begin{array}{c}\text { No } \\
\text { Complications }\end{array}$ & $9(100 \%)$ & $22(95.7 \%)$ & $13(92.9 \%)$ \\
\hline 3 & \multicolumn{2}{|c|}{ Flap Survival } & $100 \%$ & $100 \%$ & $100 \%$ \\
\hline
\end{tabular}

the appearance and sensory-motor function of the heel to the maximum extent possible. The method of repair adopted is directly correlated with the therapeutic effectiveness, which affects the long-term quality of work and life for the patients. Crowe ${ }^{16}$ conducted a literature review of methods for the reconstruction of the lateral plantar region of the foot, covering 280 publications with a total of 2684 cases. Skin flap grafts were adopted in $10 \%$ of these cases, and localized regional pedicled flaps were used in $53 \%$ of these cases, free flaps in $32 \%$, and composite methods of reconstruction in 5\%. Simple heel defects were the most common complaint, accounting for approximately $73 \%$ of the cases. The most commonly adopted pedicled flap was the distal pedicled sural neurovascular flap, and the most commonly used free flap was the latissimus dorsi flap, both of which can restore protective sensation.

For a heel wound, different flaps can be used for repair, and each flap has advantages and disadvantages. To make the best choice, the pros and cons should be weighed repeatedly, and the basic principle is to sacrifice the least for the maximum functional and cosmetic recovery. The physiological functions and anatomical characteristics of the skin in the weight-bearing and non-weight-bearing areas of the heel differ greatly, and therefore, there exist different priorities in selecting the flaps adopted to repair wounds in each area.
The skin of the weight-bearing zone (the heel plantar zone) cushions shock and impact, counteracts shear forces, and transmits sensory information to establish a coordinated response that facilitates the maintenance of body balance during walking. The flap should be wear-resistant, pressureresistant, and sensory and should preferably also be the same or similar to the skin structure of the defect area. According to Ruiz, ${ }^{2}$ the principle of proximity and simplicity should be followed to select (muscle) flaps with sufficient blood supply, an appropriate amount of soft tissue, a good cushioning effect, and resistance to friction for repair. We believe that the preferred flap for a simple repair of the plantar region of the heel should be the medial plantar island flap. If the trauma is deep or combined with osteomyelitis, the abductor pollicis could be used to form a myocutaneous flap. The medial plantar island flap was first reported by Morrison ${ }^{17}$ in 1983 and has since been widely adopted. The flap is supplied by the medial plantar artery, which begins at the posterior tibial artery and then travels on the deep surface of the abductor pollicis, branching into two branches, as the deep branch and the superficial one. The superficial branch travels on the deep surface of the superficial fascia at the medial edge of the foot, supplying the skin and superficial muscles on the medial side of the plantar, and the deep branch travels between the abductor pollicis and the toe dorsiflexors. Schwarz and Negrini ${ }^{18}$ found that the medial plantar artery emits the superficial 
branches that anastomose with the peripheral vessels of the medial tarsal artery and the communicating branches of the first metatarsal artery to form a network, forming the anatomical basis of the flap. Currently, the medial plantar island flap is considered to be the best option for repairing defects in the weight-bearing area of the heel. ${ }^{19-21}$ In the present study, nine cases were repaired using medial plantar island flaps, including two cases with defects in the medial heel, four cases on the metatarsal side, and three cases on the posterior side. In all cases, relatively satisfactory therapeutic results were achieved, and the appearance, color, and texture of the plantar area of the heel were close to normal. In all cases, a certain thickness of the keratin layer was formed with no sliding after weight-bearing and other conditions; no pressure ulcers or other complications; and good recovery of the sensory function of the plantar area of the heel, with a 2PD of 5-9 $\mathrm{mm}$. In the case of joint area injury, after applying other flaps, although the wound was repaired, the flap texture and sensory recovery were not ideal because the tissue structure of the flap was different from the plantar skin, and these patients needed to wear functional insoles for a long time to prevent complications, such as pressure ulcers. Although the lateral plantar flap and the superior medial ankle perforator flap could repair the area, they were not adopted as the primary choice because of the tissue structure, function, and risk.

The skin of the non-weight-bearing area (inner, outer, and posterior heel) covers important tissues such as the calcaneus, tarsal canal, and Achilles tendon. The requirements for repairing wounds in this area are different from the weight-bearing area. The flap does not need to be particularly resistant to wear and pressure, and the shape is important to ensure that it does not interfere with daily life, such as wearing shoes and socks, due to the swelling. Therefore, the distal pedicled flaps such as the sural neurovascular flap, the superior medial ankle perforator flap, and the superior lateral ankle perforator flap should be preferred. The sural neurovascular flap was first anatomically and clinically studied by Masquelet et $\mathrm{al}^{22}$ and Bertelli et al. ${ }^{23}$ According to Sun Shizhen et al, ${ }^{24}$ two longitudinal vascular networks exist that accompany the sural nerve, one is a chain anastomosis formed by the segmental vessels adjacent to the sural nerve and the other is an anastomotic network formed by the nutrient vessels within the nerve. Each vascular network sends out branches to form an anastomosis with the adjacent fascial vascular network, which forms the anatomic basis of the flap. Currently, the sural neurovascular flap is considered to be the conventional choice for repairing moderate defects of up to $338 \mathrm{~cm} 2$ in the peri-ankle and heel regions. ${ }^{25,26}$ In the present study, the sural neurovascular flaps were adopted in 23 cases, for defects in the outer heel $(n=6)$, posterior heel $(n=6)$, and joint region $(n=11)$. The sural neurovascular flaps were primarily adopted to repair Achilles tendon ruptures, bones with postoperative wound infection, and Achilles tendon exposure with calcaneus fracture. Of these cases, one with distal partial necrosis was healed by dressing exchange, and mild swelling were found in four cases. Although intraoperative anastomosis of the proximal part of the lateral sural cutaneous nerve was conducted, the 2PD was 9-12 $\mathrm{mm}$ at the one-year follow-up, with restored protective sensation, no advantage was found with using this method over the flap without anastomosis of the nerve that was previously conducted by the authors. Although other perforator flaps could cover the wounds, these were mainly adopted by the authors for peri-ankle tissue defects, and were not often adopted in the heel area, considering the factor of the vascular pedicle.

For cross-regional traumatic skin and soft tissue defects of the heel that cover a relatively large area, the free (muscle) flap is sometimes the best choice, considering the resection of the donor area, degree of functional impairment, surgical position, and other factors, although a reverse flap of the lower limb can also be used. The anterolateral thigh flap was first reported by Xu et $\mathrm{al}^{27}$ and Luo et $\mathrm{al}^{28}$ in 1984 and has become one of the most commonly used flaps in plastic and microsurgery. The blood supply comes from the descending branch of the lateral femoral circumflex artery, which emanates from the medial and lateral branches, slightly above the midpoint of the line from the anterior superior iliac spine to the upper outer edge of the patella. The first musculocutaneous perforator artery branch is the thickest, with an external diameter of $0.5-1.0 \mathrm{~mm}$. The vast majority of the perforation points are located within a circle with a radius of $3 \mathrm{~cm}$ centered at the midpoint of the line connecting the anterior superior iliac spine and the upper outer edge of the patella and mostly concentrated in the outer lower quarter of the circle. There are three common types of cutaneous arteries: the musculocutaneous perforator branch, the cutaneous branch of the intermuscular space, and the direct cutaneous artery. The area of the resected flap can be up to $15 \times 38 \mathrm{~cm}^{29}$ In the present study, the anterolateral thigh flaps were adopted in 14 cases, in which they were used to repair defects in the joint zone. For repairs involving the weight-bearing areas of the heel, a perforator flap was often adopted, as it does not carry the broad fascia, exhibits 
reliable healing, and can prevent excessive postoperative sliding. Routine anastomosis of the dermatomal nerve was conducted simultaneously, with a 2PD of 8-14 mm during follow-up and a restoration of protective sensation.

Summarizing this research, the "5-zone method" proposed by the author can provide quick guidance for the selection of skin flaps. We found that the medial plantar island flap is suitable for small $(<5 \mathrm{~cm})$ defects in the medial, posterior and plantar areas of the heel; the distally pedicled sural nerve nutrient vessel flap is suitable for the lateral, posterior and medium-scale heel $(6-10 \mathrm{~cm})$ joint area defect; free anterolateral thigh (perforator) flap is suitable for large area $(>10 \mathrm{~cm})$ joint area defect. In addition, on the basis of partitioning, we still need to consider the following factors: (1) heel sensation, motor function, and aesthetics; (2) size, location, depth of trauma, and the vascularity of the surrounding skin and lower limb; (3) the effect of surgery on the function and appearance of the flap-donor limb; (4) the risks associated with various flap operations; (5) the age, general condition, and requirements of the patient; and (6) the doctor's experience and surgical skills.

With the development of microsurgery technology, the repair method for heel tissue defects is constantly improving. The choice of skin flaps should be particularly cautious. After this research, we believe that the "5-zone method" has certain clinical application value and is worthy of promotion.

\section{Ethics Approval and Consent to Participate}

This study was conducted with approval from the Ethics Committee of The Third Affiliated Hospital of Inner Mongolia Medical University. This study was conducted in accordance with the declaration of Helsinki. Written informed consent for publication of the case details and images to the manuscript was obtained from all participants.

\section{Disclosure}

The authors declare that they have no conflicts of interests.

\section{References}

1. Baumeister S, Germann G. Soft tissue coverage of the extremely traumatized foot and ankle. Foot Ankle Clin. 2001;6(4):867-903.

2. Benito-Ruiz J, Yoon T, Guisantes-Pintos E, et al. Reconstruction of soft-tissue defects of the heel with local fasciocutaneous flaps. Ann Plast Surg. 2004;52(4):380-384. doi:10.1097/01. sap.0000105520.24063.bb
3. Stevenson TR, Greene TL, Kling TF Jr. Heel reconstruction with the deep circumflexiliac artery osteocutaneous flap. Plast Reconstr Surg. 1987;79(6):982-986. doi:10.1097/00006534-198706000-00023

4. Liang W, Tan BK. Use of the cross-leg distally based sural artery flap for the reconstruction of complex lower extremity defects. Arch Plast Surg. 2019;46(3):255-261. doi:10.5999/aps.2017.00892

5. Gang RK. Reconstruction of soft tissue defect of the posterior heel with a lateral calcaneal artery island flap. Plast Reconstr Surg. 1987;79(3):415-421. doi:10.1097/00006534-19870300000017

6. Hartrampf CR, Scheflan M, Bostwick J. The flexor digitorum brevis muscle island pedicle flap: a new dimension in heel reconstruction. Plast Reconstr Surg. 1980;66(2):264-270. doi:10.1097/00006534198008000-00016

7. Tee R, Jeng SF, Chen CC, et al. The medial sural artery perforator pedicled propeller flap for coverage of middle-third leg defects. $J$ Plast Reconstr Aesthet Surg. 2019;72(12):1971-1978. doi:10.1016/j.bjps.2019.08.006

8. Hollenbeck ST, Woo S, Komatsu I, et al. Longitudinal outcomes and application of the subunit principle to 165 foot and ankle free tissue transfers. Plast Reconstr Surg. 2010;125(3):924-934. doi:10.1097/ PRS.0b013e3181cc9630

9. Hallock GG. The mangled foot and ankle: soft tissue salvage techniques. Clin Podiatr Med Surg. 2014;31(4):565-576. doi:10.1016/j.cpm.2014.06.006

10. Chen Q, Li HX. Heel partition and heel skin defect repair. Chin J Modern Surg. 2005;2(13):1166-1168.

11. Wang ZZ. Editor-in-Chief. Foot and Ankle Surgery[M]. Beijing: People's Medical Publishing House; 2014:556-557.

12. Zhang YZ. Editor-in-Chief. Minimally Invasive Treatment of Calcaneal Fractures[M]. Beijing: People's Medical Publishing House; 2015:228-230.

13. Wang CL, Shau YW, Hsu TC, et al. Mechanical properties of heel pads reconstructed with flaps. Bone Joint Surg. 1999;81(2):207-211. doi:10.1302/0301-620X.81B2.0810207

14. Thoolen M, Ryan TJ, Bristow I. A study of the skin of the sole of the foot using high-frequency ultrasonography and histology. Foot. 2000;10(1):14-17. doi:10.1054/foot.1999.0568

15. Cavanaugh PR. Plantar soft tissue thickness during ground contact in walking. $J$ Biomech. 1999;32(1):623-628. doi:10.1016/S00219290(99)00028-7

16. Crowe CS, Cho DY, Kneib CJ, et al. Strategies for reconstruction of the plantar surface of the foot: a systematic review of the literature. Plast Reconstr Surg. 2019;143(5):1223. doi:10.1097/ PRS.0000000000005448

17. Morrison WA, Crabb DM, O'Brien BM, Jenkins A. The instep of the foot as a fasciocutaneous island as a free flap for heel defects. Plast Reconstr Surg. 1983;72:55. doi:10.1097/00006534198307000-00013

18. Schwarz RJ, Negrini JF. Medial plantar artery island flap for heel reconstruction. Ann Plast Surg. 2006;57(6):658-661. doi:10.1097/01. sap.0000235426.53175.e3

19. Gu J, Huan A, Zhang N, et al. Reconstruction of heel soft tissue defects using medial plantar artery island pedicle flap: clinical experience and outcomes analysis. J Foot Ankle Surg. 2016;56(2):226-229. doi:10.1053/j.jfas.2016.11.022

20. Park JS, Lee JH, Lee JS, et al. Medialis pedis flap for reconstruction of weight bearing heel. Microsurgery. 2017;37(7):780-785. doi: $10.1002 /$ micr.30198

21. Kadam D. Microsurgical reconstruction of plantar ulcers of the insensate foot. $J$ Reconstr Microsurg. 2016;32(5):402-410. doi:10.1055/s-0036-1579536

22. Masquelet AC, Romana MC, Wolf G. Skin island flaps supplied by the vascular axis of the sensitive superficial nerves: anatomical study and clinical experience in the leg. Plast Reconstr Surg. 1992;89 (6):1115-1121. doi:10.1097/00006534-199206000-00018 
23. Bertelli JA, Khouy I. Neurocutaneous island flap in the hand: anatomical basis and preliminary. Br J Plast Surg. 1992;45:586. doi:10.1016/0007-1226(92)90024-R

24. Zhong SZ, Xu YQ, Zhou CM, et al. Anatomical basis and nomenclature of cutaneous neurotrophic vascular flap. Chin J Microsurg. 1999;01:37-39.

25. Farooq HU, Ishtiaq R, Mehr S, et al. Effectiveness of reverse sural artery flap in the management of wheel spoke injuries of the heel. Cureus. 2017;9(6):e1331.

26. Luen KK, Azman W, Sulaiman W. Functional outcomes after heel pad reconstruction: a review of 7 cases. J Foot Ankle Surg. 2017;56 (5):1114-1120. doi:10.1053/j.jfas.2017.04.024
27. Xu DC, Zhong SZ, Liu MZ, et al. Anatomy of the anterolateral thigh flap[J]. J Clin Appl Anat. 1984;2(3):158-163.

28. Luo LS, $\mathrm{Xu} \mathrm{DC}$, Zhao KS, et al. Anatomical basis and clinical application of anterolateral thigh flap[J]. Chin J Plastic Burn Surg. 1985;02:50-52+78-79.

29. Lee Y-C, Chen W-C, Chou T-M. Anatomical variability of the anterolateral thigh flap perforators: vascular anatomy and its clinical implications. Plast Reconstr Surg. 2015;135(4):1097-1107. doi:10.1097/PRS.0000000000001103

\section{Publish your work in this journal}

The International Journal of General Medicine is an international, peer-reviewed open-access journal that focuses on general and internal medicine, pathogenesis, epidemiology, diagnosis, monitoring and treatment protocols. The journal is characterized by the rapid reporting of reviews, original research and clinical studies across all disease areas. The manuscript management system is completely online and includes a very quick and fair peer-review system, which is all easy to use. Visit http://www.dovepress.com/ testimonials.php to read real quotes from published authors.

Submit your manuscript here: https://www.dovepress.com/international-journal-of-general-medicine-journal 